\title{
Procalcitonin-guided antibiotic therapy for septic patients in the surgical intensive care unit
}

\author{
John Alfred Carr
}

\begin{abstract}
In critically ill patients, elucidating those patients with the systemic inflammatory response syndrome (SIRS) from an infectious source (sepsis), versus those who have SIRS without infection, can be challenging since the clinical features are the same. Even with strict monitoring and testing, 39-98\% of patients with SIRS will never have bacteriological confirmation of an infection, and $6-17 \%$ of patients with a documented infection will not show signs of SIRS. Due to this overlap, an extensive amount of research has been performed to investigate ways of determining and separating SIRS from infection, compared to SIRS due to trauma, surgical stress, or other non-infectious causes. This review article will discuss the recommended and peer-approved use of procalcitonin in septic patients in the intensive care unit and its use as a guide to antibiotic initiation and termination. The article will focus on the prospective randomized trials (Level 1 evidence) that have been conducted, and lesser levels of evidence will be referenced as needed to substantiate a conclusion. The literature documents multiple benefits of using procalcitonin as a guide to cost savings and appropriate termination of antibiotics by its use as a new objective marker of bacteremia that was previously not available. This article will show that antibiotics should be terminated when the procalcitonin level falls below $0.5 \mathrm{ng} / \mathrm{mL}$.
\end{abstract}

\section{Introduction}

In critically ill patients, elucidating those patients with the systemic inflammatory response syndrome (SIRS) from an infectious source (sepsis), versus those who have SIRS without infection, can be challenging since the clinical features are similar [1,2]. Even with strict monitoring and testing, 39-98 \% of patients with SIRS will never have bacteriological confirmation of an infection, and $6-17 \%$ of patients with a documented infection will not show signs of SIRS [3]. Due to this overlap, an extensive amount of research has been performed to investigate ways of determining and separating SIRS from infection, compared to SIRS due to trauma, surgical stress, or other non-infectious causes.

The impetus behind this research is founded, since the mortality rate for patients in septic shock increases by $7 \%$ per hour within the first $6 \mathrm{~h}$ of delayed antibiotic administration [4]. And those patients with sepsis from ventilator-associated pneumonia who had a delay of more than $24 \mathrm{~h}$ after diagnosis until initiation of antibiotics had a sevenfold higher mortality rate

Correspondence: heartandbones@yahoo.com

Department of Trauma and Critical Care, Allegiance Health, 205 N. East Street, Professional Bldg. Ste 203, Jackson, MI 49201, USA compared to those started on adequate therapy earlier [5]. Thus, it is paramount that patients developing SIRS are quickly screened to ensure an underlying infectious process is not overlooked. The Surviving Sepsis Campaign recommends blood cultures and "imaging studies performed promptly" as screening tools to determine the infectious source [6]. However, blood cultures require days in order to obtain results, and imaging studies are not comprehensive in ruling out an infectious source. This has led to the search for an appropriate serum biomarker to determine and differentiate sepsis from SIRS.

Extensive research looking for the right serum biomarker has covered many potential candidate markers, but the most extensively researched have been interleukin-6, interleukin-8, interleukin-10, C-reactive protein (CRP), and procalcitonin [7-9]. Most of this research has concluded that IL-6, IL-8, IL-10, and CRP are non-specific in separating SIRS due to infection from non-infectious SIRS. However, procalcitonin levels are only mildly elevated in SIRS but become significantly elevated in sepsis and dramatically elevated with Gramnegative sepsis $[10,11]$. This finding, although initially 
reported by Assicot back in 1993, continued to mostly be under-utilized in the care of septic patients until recently, when the research in this area has greatly improved [12].

This review article will discuss the recommended and peer-approved use of procalcitonin in septic patients in the intensive care unit (ICU) and its use as a guide to antibiotic initiation and termination. Due to the voluminous research on procalcitonin and in order to draw appropriate conclusions from the data, this review article will focus only on the use of procalcitonin in septic patients in an ICU setting. Since the procalcitonin level is much higher in septic patients than those with an isolated pulmonary infection, results from these overlapping studies (pulmonary infection without sepsis, pulmonary infection with sepsis, and non-pulmonary sepsis) will be addressed and compared to substantiate the cutoff levels of procalcitonin and its appropriate use as a biomarker of sepsis. The article will focus on the prospective randomized trials (Level 1 evidence) that have been conducted, and lesser levels of evidence will be referenced as needed to substantiate a conclusion.

The literature documents multiple benefits of using procalcitonin as a guide to cost savings and appropriate termination of antibiotics by its use as a new objective marker of bacteremia that was previously not available. This article will show that previous "standard" courses of treatment based upon a pre-set number of 10, 14, or 21 days are no longer appropriate in septic patients and that antibiotics should be terminated when the procalcitonin level falls below $0.5 \mathrm{ng} / \mathrm{mL}$.

\section{Review}

\section{Molecular physiology}

Procalcitonin is the prohormone of calcitonin, but unlike calcitonin which is induced by hypercalcemia, procalcitonin is induced by the activation and adherence of monocytes to the endothelial layer of blood vessels as occurs during sepsis [13, 14]. Unlike cytokines, which can rise and fall due to multiple overlapping and mitigating physiological interactions, procalcitonin release is more tightly controlled and only found in the systemic circulation during response to severe stress and sepsis [14-16]. Multiple research studies have compared procalcitonin to C-reactive protein, cytokines (IL-6, IL-8, IL-10), and lactate, and all of these studies (except one, ref. [17]) have found that procalcitonin was much more sensitive and specific in accurately diagnosing sepsis, and the resolution of sepsis, than any of the other markers $[1,2,7-9,12,18,19]$. In addition, it is useful that procalcitonin levels in normal individuals are very low $(<0.1 \mathrm{ng} / \mathrm{mL})$ [14]. Thus, there is substantial evidence that procalcitonin is a reliable marker of sepsis and certainly the best of the biomarkers yet to be identified.

\section{Prospective randomized trial results}

Having established that procalcitonin is a marker of sepsis, the basic science research was supported and upheld by nine prospective randomized trials and refuted by one prospective randomized trial (Tables 1 and 2) [20-29]. Thus, there have been a total of ten prospective randomized trials, and nine have published results (refs. $[20-27,29])$, and the tenth trial has closed, but the results have not yet been published at the time of this writing (ref. [28]). It is important to note that not all of the trials were performed in the same patient populations, and therefore, the studies will be grouped and discussed by the population they examined.

\section{Pneumonia and respiratory infection}

Three of the trials enrolled patients with acute respiratory infections or community-acquired pneumonia [20, 23, 26]. One enrolled only patients with ventilator-associated pneumonia and will be discussed separately [25]. These four studies represent pulmonary infection without sepsis. These trials are an important comparative group (without sepsis) to examine against the trials that studied procalcitonin in septic patients.

In all of these trials, an algorithm was followed to determine the initiation and duration of antibiotic therapy based upon serial procalcitonin levels and discontinuation of antibiotics when the procalcitonin level dropped below a pre-determined cutoff level. The three studies examining the use of procalcitonin in guiding therapy for acute respiratory infections and communityacquired pneumonia all reported similar conclusions. All three studies used the same cutoff level of $0.25 \mu \mathrm{g} / \mathrm{L}$ or less as the point to stop antibiotics. And all three concluded that procalcitonin reduced total antibiotic exposure, reduced antibiotic treatment duration, and created similar treatment success in experimental and control groups, and no increased risk was found in stopping the antibiotics once the procalcitonin level normalized. Two of the three also showed that the procalcitonin level was effective in preventing the initial use of antibiotics when the level was initially normal $(<0.25 \mu \mathrm{g} / \mathrm{L})[20,23]$. These studies showed a median decrease in antibiotic treatment duration of 7,1 , and 3 days, respectively.

In the one trial studying exclusively those patients with ventilator-associated pneumonia (VAP), the inclusion criteria for diagnosis and the standard treatment of VAP were based upon the previously published guidelines [30]. The procalcitonin cutoff level to stop antibiotics was slightly higher than in the other trials at $0.5 \mu \mathrm{g} / \mathrm{L}$ or less [25]. The authors concluded that procalcitonin allowed a reduction in the overall duration of antibiotic therapy and overall patient exposure to antibiotics. The median decrease in antibiotic treatment was 5 days in the procalcitonin group. The rate of discontinuation of 
Table 1 Results of prospective randomized trials

\begin{tabular}{|c|c|c|c|c|c|c|c|c|c|}
\hline Country & Author & Ref & Trial name & Year & Number & Population & PCT E & PCT C & Number of fewer days of antibiotic use \\
\hline \multicolumn{10}{|c|}{ Use in respiratory infections } \\
\hline Switzerland & Christ-Crain & [20] & None & 2006 & 302 & CAP & 0.57 & 0.44 & Yes, 7 days \\
\hline Switzerland & Briel & [23] & None & 2008 & 458 & resp infect & 0.8 & 0.8 & Yes, 1 day \\
\hline Swiss/USA & Stolz & [25] & None & 2009 & 101 & VAP & 0.6 & 0.7 & Yes, 5 days \\
\hline Switzerland & Schuetz & [26] & ProHosp & 2009 & 1359 & resp infect & 0.24 & 0.24 & Yes, 3 days \\
\hline \multicolumn{10}{|l|}{ Use in sepsis } \\
\hline Switzerland & Nobre & [21] & None & 2008 & 79 & Sepsis & 8.4 & 5.9 & Yes, 3.5 days \\
\hline Germany & Schroeder & {$[22]$} & None & 2008 & 27 & Severe sepsis & 7.0 & 6.0 & Yes, 1.7 days \\
\hline \multicolumn{10}{|c|}{ Sepsis in the ICU setting } \\
\hline Germany & Hochreiter & [24] & None & 2009 & 110 & SICU & 4.5 & 4.8 & Yes, 2 days \\
\hline France & Bouadma & [27] & PRORATA & 2010 & 621 & $\mathrm{ICU}$ & 12.0 & 12.0 & Yes, 3 days \\
\hline Netherlands & De Jong & [28] & SAPS & 2013 & 1816 & $\mathrm{ICU}$ & - & - & Results pending \\
\hline Australia & Shehabi & [30] & ProGuard & 2014 & 400 & $\mathrm{ICU}$ & 5.7 & 8.8 & No, 2 days not statistically significant \\
\hline
\end{tabular}

Ref reference number, $n$ number of patients enrolled in the study, CAP community-acquired pneumonia, resp infect respiratory infection, SICU surgical intensive care unit, VAP ventilator-associated pneumonia, ICU intensive care unit, PCT E initial procalcitonin level in the experimental group (ng/mL), PCT C initial procalcitonin level in the control group $(\mathrm{ng} / \mathrm{mL})$

antibiotics overall was also higher in the procalcitonin group. The groups had a similar number of mechanical ventilation days and ICU days. Morbidity and mortality levels were also similar. No increased risk of adverse events was found by discontinuing antibiotics using the procalcitonin-guided algorithm.

\section{Sepsis in the ICU setting}

Four of the prospective randomized trials focused on septic patients (from any source) in an ICU setting, and these trials will be considered together [21, 22, 24, 27]. In all four trials, an algorithm was followed using procalcitonin to guide the duration of antibiotic therapy and to continue antibiotic therapy based upon serially elevated procalcitonin levels until the procalcitonin level dropped below a pre-determined value. At that point, antibiotics were discontinued. Both the procalcitonin group and the control group had a baseline procalcitonin level measured upon initial presentation and inclusion into the study, but only the experimental group had serial procalcitonin levels checked to guide treatment. The control groups were treated by standard courses of antibiotics until the patient was clinically determined to have resolved their septic process.

In all four trials, sepsis was defined appropriately and documented with the Simplified Acute Physiology Score (SAPS II) and the Sequential Organ Failure Assessment (SOFA) score. The rates of microbiologically confirmed

Table 2 Results of prospective randomized trials

\begin{tabular}{|c|c|c|c|c|c|}
\hline Country & Author & Ref & Trial name & Year & Conclusions \\
\hline \multicolumn{6}{|c|}{ Use in respiratory infections } \\
\hline Switzerland & Christ-Crain & {$[20]$} & None & 2006 & PCT level prevented initial antibx use, earlier discontinuation antibx, less overall use \\
\hline Switzerland & Briel & {$[23]$} & None & 2008 & PCT level prevented initial antibx use, decreased overall antibx exposure and duration \\
\hline Swiss/USA & Stolz & {$[25]$} & None & 2009 & PCT level allowed earlier discontinuation antibx, decreased total exposure and duration \\
\hline Switzerland & Schuetz & {$[26]$} & ProHosp & 2009 & adverse outcomes similar, PCT group had fewer adverse events, less total antibx use \\
\hline \multicolumn{6}{|l|}{ Use in sepsis } \\
\hline Switzerland & Nobre & {$[21]$} & None & 2008 & PCT allowed earlier discontinuation of antibx, decreased overall antibx exposure \\
\hline Germany & Schroeder & {$[22]$} & None & 2008 & PCT allowed earlier discontinuation of antibx, cost of antibx reduced \\
\hline \multicolumn{6}{|c|}{ Use in sepsis in the ICU setting } \\
\hline Germany & Hochreiter & {$[24]$} & None & 2009 & PCT allowed earlier discontinuation of antibx, shorter ICU length of stay \\
\hline France & Bouadma & {$[27]$} & PRORATA & 2010 & PCT allowed earlier discontinuation of antibx, decreased overall antibx exposure \\
\hline Netherlands & De Jong & {$[28]$} & SAPS & 2013 & No longer recruiting patients, results pending \\
\hline Australia & Shehabi & {$[30]$} & ProGuard & 2014 & PCT group had 2 less days of antibx but not statistically significant \\
\hline
\end{tabular}

Ref references, $P C T$ procalcitonin, antibx antibiotics 
sepsis and sepsis severity scores were similar between the procalcitonin-guided and control groups. The median procalcitonin levels on admission to the ICU were similar between the groups and are listed in Table 1.

However, the initial procalcitonin levels are all significantly higher in the sepsis trials and the sepsis-in-the-ICUsetting trials, compared to the respiratory infection/pneumonia trials (Table 1). The procalcitonin levels in the sepsis-ICU-setting trials ranged from 4.5 to $12.0 \mathrm{ng} / \mathrm{mL}$ compared to $0.24-0.8 \mu \mathrm{g} / \mathrm{L}$ in the respiratory infection/ pneumonia patients. Clearly, the septic patients in the ICU setting were more toxic, and this is reflected in the higher procalcitonin levels. While some authors report procalcitonin levels in microgram per liter $(\mu \mathrm{g} / \mathrm{L})$ and some report the levels in nanogram per milliliter $(\mathrm{ng} / \mathrm{mL})$, the reader should be aware that these are, in fact, the same amount, i.e., $1 \mathrm{ng} / \mathrm{mL}$ equals $1 \mu \mathrm{g} / \mathrm{L}$.

The procalcitonin cutoff level for discontinuation of antibiotics was different in all of the ICU-setting trials. In two trials, the cutoff level for discontinuation of antibiotics was $<1 \mathrm{ng} / \mathrm{mL}$ or less than $35 \%$ of the initial value within 3 days $[22,24]$. This level was similar in the two studies because the Schroeder study [22] appears to be a subgroup analysis of the same patients during the same time period by the same authors as the Hochreiter study [24].

In the other two trials, the cutoff level for discontinuation of antibiotics was $<0.25 \mu \mathrm{g} / \mathrm{L}$ or a drop of more than $90 \%$ of the peak level in one trial and $<0.5 \mu \mathrm{g} / \mathrm{L}$ or a drop of more than $80 \%$ of the peak concentration in the other [21, 27]. What the appropriate cutoff level should be will be discussed later in the manuscript.

Despite the differences in what value would determine discontinuation of antibiotics, all four trials drew similar conclusions. In all studies, the duration of antibiotic treatment was significantly shorter in the procalcitonin-guided groups. The median reduction in antibiotic treatment days was $3.5,1,2$, and 3 days, respectively [21, 22, 24, 27]. Overall antibiotic exposure was also less in the procalcitonin-guided patients. And none of the trials showed an increase in adverse events or treatment failure rates due to fewer antibiotic days. The Schroeder study also concluded procalcitonin significantly reduced the cost of antibiotics by $18 \%$, and the Nobre trial showed a statistically significant shorter ICU length of stay [21, 22]. Cure rates, morbidity, and mortality rates were similar between the groups in all of the trials.

One significant concern with a procalcitonin-guided algorithm to stop antibiotics is that a persistently septic patient will have antibiotics discontinued prematurely, resulting in recurrence of infection or other sepsisrelated morbidity. This issue was addressed in two of the trials [21, 27], and their secondary endpoints are worth noting in terms of recurrence of infection. The Nobre trial showed that in those patients with a positive blood culture who were assigned to the procalcitonin arm and received a shorter course of antibiotics, no case of recurrent infection was observed after the procalcitonin level had dropped below the cutoff level $(0.25 \mu \mathrm{g} / \mathrm{L})$ [21] Similarly, in the PRORATA trial, in the procalcitoninguided arm, no deaths were recorded as related to relapse of infection after discontinuation of antibiotics (cutoff level $0.5 \mu \mathrm{g} / \mathrm{L}$ ) [27].

In the PRORATA trial, 28 patients with clinical signs of SIRS assigned to the procalcitonin arm, and 15 patients assigned to the control arm, had initial levels $<0.5 \mathrm{ng} / \mathrm{mL}$ and were therefore not treated with antibiotics at inclusion into the study. Of the 28 in the procalcitonin arm, eight patients showed a subsequent increase in their procalcitonin level and were later given antibiotics by day 5 (20 patients were never given antibiotics), and there was one death on hospital day 18 from comorbidities. The remainder of the patients did well. Of the 15 patients in the control arm not given antibiotics at inclusion and not having serial procalcitonin levels checked, eight patients were later treated with antibiotics (within 5 days due to clinical deterioration) and four died. The authors concluded that, in terms of mortality, the procalcitonin arm was non-inferior to the control group [27].

Unlike the four prospective randomized trials in a sepsis-ICU-setting mentioned above, there was one prospective randomized trial performed in ICUs in Australia which had negative results [29]. Called the ProGuard trial, this trial was different from the other four ICUsetting trials because the procalcitonin cutoff level to stop antibiotics was set very low at $0.1 \mathrm{ng} / \mathrm{mL}$. This is a normal value [14]. The authors found that with a cutoff level of $0.1 \mathrm{ng} / \mathrm{mL}$, the procalcitonin group did have a median of 2 less days of antibiotics, but this was not significant $(p=0.58)$ [29]. The authors concluded that a procalcitonin algorithm using a $0.1 \mathrm{ng} / \mathrm{mL}$ cutoff does not achieve a significant $(>25 \%)$ reduction in antibiotic duration.

\section{Determining the appropriate level to discontinue antibiotics}

As the ProGuard trial proved, finding the appropriate cutoff value to stop antibiotics is the yet-to-be-determined critical piece of information that is currently unknown. The Nobre trial showed that a cutoff level of $0.25 \mu \mathrm{g} / \mathrm{L}$ was safe to stop antibiotics, since no recurrent infections were reported after stopping antibiotics at that level [21]. However, a higher cutoff level of $0.5 \mu \mathrm{g} / \mathrm{L}$ was also shown to be safe, with no recurrent infections reported at that level, and that level also allowed a significant reduction in antibiotic usage [27]. With the cutoff level sets too low at $0.1 \mathrm{ng} / \mathrm{mL}$, as in the ProGuard trial, no significant benefit was observed. 
Based upon the findings of all of these prospective randomized trials combined, the appropriate cutoff level to stop antibiotics in septic patients in an ICU setting appears to be a serum concentration of procalcitonin of $<0.5 \mathrm{ng} / \mathrm{mL}$. This number was successfully used as the cutoff level to stop antibiotics in two of the prospective trials [25, 27], and two trials that used an even higher level of $1.0 \mathrm{ng} / \mathrm{mL}$ also reported successful outcomes, although this level is not as frequently cited, and considered too high by other researchers [22, 24]. The $0.5 \mathrm{ng} /$ $\mathrm{mL}$ level was also successfully used as an initial threshold not to start antibiotics upon enrollment in three trials [25-27]. With antibiotics withheld at this range, the patients still had successful outcomes.

In order to add more support to using a level $<0.5 \mathrm{ng} /$ $\mathrm{mL}$ as the cutoff level to stop antibiotics in septic ICU patients, it is helpful to also outline what the literature shows as regards the procalcitonin level that becomes diagnostic, or at least more indicative, of sepsis. The cutoff level to stop antibiotics needs to be well below the diagnostic level at which sepsis is confirmed.

\section{The procalcitonin level diagnostic of sepsis}

In addition to the prospective randomized trials already discussed, there have been an additional 25 prospective non-randomized studies investigating the appropriate level of procalcitonin that is diagnostic of sepsis in ICU patients $[9,18,31-53]$. Since the procalcitonin level has been shown to be consistently higher in septic patients, than those with only bacteremia, respiratory infections, or pneumonia, the ability to find an appropriate diagnostic range is enhanced in this population. And therefore, the results of those studies that focused on patients in the emergency department setting, medical wards, and outpatients have been excluded.

The results of those studies that investigated the procalcitonin level diagnostic of sepsis in ICU populations are shown in Table 3 with the procalcitonin levels separated in

Table 3 Procalcitonin diagnostic levels for sepsis in prospective studies in ICU populations

\begin{tabular}{|c|c|c|c|c|c|c|c|c|c|}
\hline Name & Year & Number & Ref & $\mathrm{PCT}<0.5$ & 0.6 to $<1.0$ & 1.1 to $<1.5$ & 1.6 to 2.0 & Sensitivity (\%) & Specificity (\%) \\
\hline Al-Nawas & 1996 & 337 & {$[32]$} & 0.5 & & & & 60 & 79 \\
\hline Bossink & 1999 & 200 & [33] & 0.5 & & & & 65 & 58 \\
\hline Sudhir & 2011 & 100 & [34] & 0.5 & & & & 94 & - \\
\hline Ugarte & 1999 & 205 & {$[35]$} & & 0.6 & & & 68 & 61 \\
\hline Muller & 2000 & 101 & {$[36]$} & & 1.0 & & & 89 & 94 \\
\hline Aouifi & 2000 & 97 & {$[37]$} & & 1.0 & & & 85 & 95 \\
\hline Ruokonen & 2002 & 208 & [38] & & 0.8 & & & 68 & 48 \\
\hline G-B & 2002 & 119 & [39] & & 1.0 & & & 95 & 65 \\
\hline Whang & 1998 & 29 & {$[40]$} & & & 1.1 & & 67 & 80 \\
\hline Oberhoffer & 2000 & 242 & {$[41]$} & & & 1.4 & & 84 & 83 \\
\hline Wanner & 2000 & 405 & {$[42]$} & & & 1.5 & & $76^{a}$ & 77 \\
\hline Harbarth & 2001 & 78 & [9] & & & 1.1 & & 97 & 78 \\
\hline Tugrul & 2002 & 85 & [43] & & & 1.3 & & 73 & 83 \\
\hline Hensler & 2003 & 137 & {$[44]$} & & & 1.5 & & $42^{\mathrm{a}}$ & 73 \\
\hline Castelli & 2004 & 150 & [18] & & & 1.1 & & 79 & 85 \\
\hline Mokart & 2005 & 50 & {$[45]$} & & & 1.1 & & 81 & 72 \\
\hline Brunkhorst & 2000 & 185 & {$[46]$} & & & & 2.0 & 96 & 86 \\
\hline Suprin & 2000 & 101 & {$[47]$} & & & & 2.0 & 65 & 70 \\
\hline Meisner & 2002 & 208 & {$[48]$} & & & & 2.0 & 87 & 78 \\
\hline DeTalance & 2003 & 108 & [49] & & & & 2.0 & 91 & 89 \\
\hline Luzzani & 2003 & 70 & {$[50]$} & & & & 2.0 & 76 & 84 \\
\hline $\mathrm{Du}$ & 2003 & 51 & {$[51]$} & & & & 1.6 & 80 & 74 \\
\hline Geppert & 2003 & 55 & {$[52]$} & & & & 2.0 & 87 & 75 \\
\hline Endo & 2008 & 82 & [53] & & & & 2.0 & 95 & 78 \\
\hline Meynaar & 2011 & 76 & {$[54]$} & & & & 2.0 & 97 & 80 \\
\hline
\end{tabular}

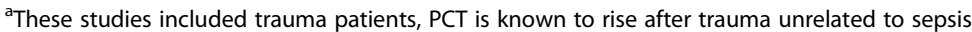
ref reference 
Table 4 Content and references

\begin{tabular}{ll}
\hline Subject & References \\
\hline Prospective randomized trials & {$[20-28,30]$} \\
Discontinuing antibiotics & {$[20-28]$} \\
Diagnosing sepsis & {$[9,18,32-54]$} \\
Differentiating sepsis and SIRS & {$[10,18,20-24,26,27,30,55-57]$} \\
Monitoring sepsis & {$[16,17,19,31,58-61]$} \\
\hline
\end{tabular}

groups of $\leq 0.5,0.6$ to $\leq 1.0,1.1$ to $\leq 1.5$, and 1.6 to 2.0 . The highest sensitivities to detect sepsis were found in those studies that made the diagnosis of sepsis based upon a procalcitonin range of $2.0 \mathrm{ng} / \mathrm{mL}$ or higher [45-49, 51-53]. In these studies, the sensitivity to detect sepsis ranged from 65 to $96 \%$, although six of the studies found the sensitivity to be greater than $86 \%[45,47,48,51-53]$. In those same studies, the specificity ranged from 70 to $89 \%[45-49,51-$ 53]. As one would expect, as the diagnostic level is dropped down to $1.5 \mathrm{ng} / \mathrm{mL}$ or $1.0 \mathrm{ng} / \mathrm{mL}$ or less, the overall sensitivity drops as well (Tables 3 and 4) [9, 18, 31-44].

With this in mind, another review of Table 1 displaying the five prospective randomized trials in septic patients that were conducted in an ICU setting shows that the initial procalcitonin level documented for the septic patients in those trials ranged from 4.5 to $12 \mathrm{ng} / \mathrm{mL}$. Thus, the diagnostic level of $2.0 \mathrm{ng} / \mathrm{mL}$ appears to be appropriate to diagnose sepsis in an ICU population, with an acceptable sensitivity and specificity.

\section{Differentiating sepsis from SIRS}

The third piece of information to be discussed is differentiating sepsis from SIRS. Although there is significant evidence supporting elevated procalcitonin in septic patients, procalcitonin levels are also mildly elevated in SIRS without infection. Several studies have addressed areas of overlap between the two.

It has been documented from the outpatient versus ICU-setting trials that the initial level of procalcitonin will be higher in a patient with sepsis compared to one with only a respiratory infection or bacteremia (Table 1). In addition, procalcitonin is not elevated in patients with a simple localized infection. While the three outpatient prospective randomized trials examining the usefulness of procalcitonin in respiratory infections did show true benefit, the procalcitonin levels were not highly elevated, and the differences between starting levels, peak levels, and the cutoff levels were quite small [20, 23, 26].

This is because every patient with an infection is not septic, and procalcitonin has shown its real value in determining when to stop antibiotics in septic patients in an ICU setting. All of the prospective randomized ICU trials showed significant elevations in the procalcitonin levels in septic patients [21, 22, 24, 27, 29]. Two observational studies that examined the differences in procalcitonin levels in patients with documented sepsis compared to SIRS found that the median level in septic patients ranged from 1.58 to $29.3 \mathrm{ng} / \mathrm{mL}$, while in the SIRS group, the median levels were $0.38-0.74 \mathrm{ng} / \mathrm{mL}$ $[10,18]$. Another study that examined baseline procalcitonin levels in patients with end-stage renal disease on hemodialysis without infection found that as their baseline inflammatory state reflects, the procalcitonin levels in these patients remained mildly chronically elevated at a median range of $0.50 \pm 0.49 \mathrm{ng} / \mathrm{mL}$ [54]. A study that investigated the procalcitonin levels in patients with neurotrauma without infection found that, depending upon the severity of the brain injury, the procalcitonin levels were mildly elevated from 0.05 to 0.13 for mild brain injury, 0.11 to 0.55 for moderate injury, and 0.17 to 0.79 for severe brain injury [55]. Overall, these studies have concluded that most patients with non-infectious SIRS maintain an inflammatory-mediated procalcitonin level from 0.3 to $0.8 \mathrm{ng} / \mathrm{mL}[10,18,54-56]$.

\section{Using procalcitonin to monitor for sepsis in the ICU: static levels versus trends}

Although older research showed that procalcitonin levels in sepsis do not correlate with mortality [17], more recent work has shown that increased mortality was documented for patients with pneumonia whose levels exceed $2.5 \mathrm{ng} / \mathrm{mL}$ and in septic trauma patients whose levels exceed $5 \mathrm{ng} / \mathrm{mL}[19,57]$. In addition, a persistent elevation in the procalcitonin level, or no decrease in the level after antibiotic treatment, has been shown to correlate with a higher mortality rate [58-61].

Thus, it is important to continue to follow the trend of the procalcitonin level while the patient is in the ICU. The level can change, and certainly, a patient initially admitted to the ICU may subsequently develop an infection, or later become septic, and the procalcitonin is a useful guide to follow. A dramatic increase in the procalcitonin level should certainly raise suspicion of an infection or worsening of an ongoing septic process. It has been recommended that if the clinical picture is indicative of sepsis, and the initial procalcitonin level is low, that antibiotics should be started anyway, and repeat procalcitonin levels checked at 12,24 , and $36 \mathrm{~h}$ until the diagnosis is clear [16].

Having now established that a level $\geq 2.0 \mathrm{ng} / \mathrm{mL}$ is most sensitive and specific for sepsis and that a level $<0.5 \mathrm{ng} /$ $\mathrm{mL}$ is safe to stop antibiotics in septic ICU patients, there is a persistent "gray area" from 0.5 to $1.9 \mathrm{ng} / \mathrm{mL}$. Most patients with SIRS have levels of $0.3-0.8 \mathrm{ng} / \mathrm{mL}$, which occupies some of this range. For now, these levels can only represent worsening or resolution of an inflammatory or septic process, depending upon which way the trend moves. Thus, the trends are very important and will need to be followed as the patient worsens or improves. 
Of course, procalcitonin is only a biomarker of sepsis, and clinical judgment is still primary in deciding upon initiation and termination of antibiotics. However, there is now substantial evidence that procalcitonin can successfully be used to guide antibiotic therapy and adds tremendous benefit in limiting the excessive use of antibiotics. This biomarker is much more physiologically reliable as an objective marker of ongoing infection, and its use is justified by prospective randomized data. A procalcitonin-based algorithm to terminate antibiotics should be more widely accepted and is superior to courses of antibiotics based upon a pre-determined number of days.

\section{Conclusions}

The following conclusions use the Oxford Centre for Evidence-Based Medicine 2009 levels of evidence:

1. In septic ICU patients, a clinically recovered physiological situation and a serum procalcitonin level less than $0.5 \mathrm{ng} / \mathrm{mL}$ appear to be an acceptable and safe time to discontinue antibiotics. (Level $1 \mathrm{~b}$ evidence)

2. The use of procalcitonin to decide when to stop antibiotics based upon a level less than $0.5 \mathrm{ng} / \mathrm{mL}$ in patients with pulmonary infections and/or sepsis has been shown to reduce total antibiotic use and decrease the duration of antibiotics. (Level $1 \mathrm{~b}$ evidence)

3. An appropriate clinical situation and a procalcitonin level above $2 \mathrm{ng} / \mathrm{mL}$ are diagnostic of sepsis with a high sensitivity and specificity, and antibiotic therapy should be started immediately. (Level 2a evidence)

4. A patient with a systemic inflammatory response and a procalcitonin level less than $0.5 \mathrm{ng} / \mathrm{mL}$ is very unlikely to have an infectious etiology of the SIRS response, and antibiotics can be withheld, although the procalcitonin level should be trended. (Level 2a evidence)

\section{Abbreviations}

CRP: C-reactive protein; ICU: intensive care unit; L: liter; $\mathrm{mL}$ : milliliter; Ng: nanogram; PCT: procalcitonin; SIRS: systemic inflammatory response syndrome; $\mu \mathrm{g}$ : microgram.

\section{Competing interests}

The author declares that he has no competing interests.

Received: 22 May 2015 Accepted: 6 July 2015

Published online: 04 August 2015

\section{References}

1. Tian G, Pan SY, Ma G, Liao W, Su QG, Qin K. Serum levels of procalcitonin as a biomarker for differentiating between sepsis and systemic inflammatory response syndrome in the neurological intensive care unit. J Clin Neurosci. 2014;21:1153-8.

2. Su L, Han B, Liu C, Liang L, Jiang Z, Xie L. Value of soluble TREM-1, procalcitonin, and $\mathrm{C}$-reactive protein serum levels as biomarkers for detecting bacteremia among sepsis patients with new fever in intensive care units: a prospective cohort study. BMC Infect Dis. 2012;12:157.

3. Klein-Klouwenberg PM, Ong DS, Bonten MJ, Cremer OL. Classification of sepsis, severe sepsis and septic shock: the impact of minor variations in data capture and definition of SIRS criteria. Intensive Care Med. 2012:38:811-9.

4. Kumar A, Roberts D, Wood KE, Light B, Parrillo JE, Cheang M. Duration of hypotension before initiation of effective antimicrobial therapy is the critical determinant of survival in human septic shock. Crit Care Med. 2006:34:1589-96

5. Iregui M, Ward S, Sherman G, Fraser VJ, Kollef MH. Clinical importance of delays in the initiation of appropriate antibiotic treatment for ventilator-associated pneumonia. Chest. 2002;122:262-8.

6. Dellinger RP and the Surviving Sepsis Campaign Guidelines Committee. Surviving sepsis campaign: international guidelines for management of severe sepsis and septic shock 2012. Crit Care Med. 2013:41:580-637.

7. Jun KR, Lee JN, Song SA, Oh SH, Kim HR. Serial changes in serum procalcitonin, interleukin 6, and C-reactive protein levels according to nonspecific surgical stimulation. Clin Chem Lab Med. 2015;53:549-58.

8. Wunder C, Eichelbronner $\mathrm{O}$, Roewer N. Are IL-6, IL-10, and PCT plasma concentrations reliable for outcome prediction in severe sepsis? A comparison with APACHE III and SAPS II. Inflamm Res. 2004;53:158-63.

9. Harbarth S, Holeckova K, Froidevaux C, Pittet D, Geneva Sepsis Network. Diagnostic value of procalcitonin, interleukin 6, and interleukin 8 in critically ill patients admitted with suspected sepsis. Am J Respir Crit Care Med. 2001;164:396-402.

10. Nakajima A, Yazawa J, Sugiki D, Mizuguchi M, Haruki K. Clinical utility of procalcitonin as a marker of sepsis: a potential predictor of causative pathogens. Intern Med. 2014;53:1497-503.

11. Plebani M, Fabbri LM. Procalcitonin-guided antibiotic therapy: a potentially effective and efficient strategy. Clin Chem Lab Med. 2015;53:519-20.

12. Assicot M, Gendrel D, Carsin H, Raymond J, Bohoun C. High serum procalcitonin concentrations in patients with sepsis and infection. Lancet. 1993;341:515-8.

13. Linscheid P, Seboek D, Schaer JD, Zulewski H, Keller U, Muller B. Expression and secretion of procalcitonin and calcitonin gene-related peptide by adherent monocytes and macrophage-activated adipocytes. Crit Care Med. 2004;32:1715-21.

14. Wiedermann FJ, Kaneider N, Egger P, Tiefenthaler W, Widedermann CJ, Linder $\mathrm{KH}$, et al. Migration of human monocytes in response to procalcitonin. Crit Care Med. 2002;30:1112-7.

15. Oberhoffer M, Stonans I, Russwurm S, Stonane E, Vogelsang H, Junker U. Procalcitonin expression in human peripheral blood mononuclear cells and its modulation by lipopolysaccharides and sepsis related cytokines in vitro. J Lab Clin Med. 1999;134:49-55.

16. Meisner M. Update on procalcitonin measurements. Ann Lab Med. 2014;34:263-73.

17. Sridharan P, Chamberlain RS. The efficacy of procalcitonin as a biomarker in the management of sepsis: slaying dragons or tilting at windmills? Surg Infect. 2013;14:489-511.

18. Castelli GP, Pognani C, Meisner M, Stuani A, Bellomi D, Sgarbi L. Procalcitonin and $C$-reactive protein during systemic inflammatory response syndrome, sepsis and organ dysfunction. Crit Care. 2004;8:R234-42.

19. Andrijevic I, Matijasevic J, Andrijevic L, Kovacevic T, Zaric B. Interleukin-6 and procalcitonin as biomarkers in mortality prediction of hospitalized patients with community acquired pneumonia. Ann Thorac Med. 2014;9:162-7.

20. Christ-Crain M, Stolz D, Bingisser R, Muller C, Miedinger D, Huber PR, Zimmerli W, et al. Procalcitonin guidance of antibiotic therapy in community-acquired pneumonia: a randomized trial. Am J Respir Crit Care Med. 2006;174:84-93.

21. Nobre V, Harbarth S, Jean-Daniel G, Rohner P, Pugin J. Use of procalcitonin to shorten antibiotic treatment duration in septic patients: a randomized trial. Am J Respir Crit Care Med. 2008;177:498-505.

22. Schroeder S, Hochreiter M, Koehler T, Schroeder S, Hochreiter M, Koehler T, Schweiger AM, Bein B, Keck FS. Procalcitonin (PCT)-guided algorithm reduces length of antibiotic treatment in surgical intensive care patients with severe sepsis: results of a prospective randomized study. Arch Surg. 2009;394:221-6

23. Briel M, Schuetz P, Mueller B, Young J, Schild U, Nusbaumer C, et al. Procalcitonin-guided antibiotic use vs standard approach for acute respiratory tract infections in primary care. Arch Intern Med. 2008;168:2000-7.

24. Hochreiter M, Kohler T, Schweiger AM, Keck FS, Bein B, von Spiegel T. Procalcitonin to guide duration of antibiotic therapy in intensive care patients: a randomized prospective controlled trial. Crit Care. 2009;13(R83):1-7. 
25. Stolz D, Smyrnios N, Eggimann P, Pargger H, Thakkar N, Siegemund M, et al. Procalcitonin for reduced antibiotic exposure in ventilator-associated pneumonia: a randomized study. Eur Respir J. 2009;34:1364-75.

26. Schuetz $P$, Christ-Crain M, Thomann R, Falconnier C, Wolbers M, Widmer I, et al. Effect of procalcitonin-based guidelines vs standard guidelines on antibiotic use in lower respiratory tract infections: the ProHOSP randomized controlled trial. JAMA. 2009;302:1059-66.

27. Bouadma L, Luyt CE, Tubach F, Cracco C, Alvarez A, Schwebel C, et al. Use of procalcitonin to reduce patients' exposure to antibiotics in intensive care units (PRORATA trial): a multicenter randomized controlled trial. Lancet. 2010;375:463-74

28. Assink De Jong E, De Lange DW, Van Oers JA, Nijsten MW, Twisk JW, Beishuizen A. Stop antibiotics on guidance of procalcitonin study (SAPS): a randomized prospective multicenter investigator-initiated trial to analyze whether daily measurements of procalcitonin versus a standard-of-care approach can safely shorten antibiotic duration in intensive care unit patientscalculated sample size: 1816 patients. BMC Infect Dis. 2013;13:178-86.

29. American Thoracic Society, Infectious Diseases Society of America. Guidelines for the management of adults with hospital-acquired, ventilator-associated, and healthcare-associated pneumonia. Am J Respir Crit Care Med. 2005;171:388-416.

30. Shehabi Y, Sterba M, Garrett PM, et al. Procalcitonin algorithm in critically ill adults with undifferentiated infection or suspected sepsis: a randomized controlled trial. Am J Respir Crit Care Med. 2014;190:1102-10.

31. Sakran JV, Michetti CP, Sheridan MG, Richmond R, Waked T, Aldaghlas T, et al. The utility of procalcitonin in critically ill trauma patients. J Trauma Acute Care Surg. 2012;73:413-8.

32. Al-Nawas B, Krammer I, Shah P. Procalcitonin in diagnosis of severe infections. Eur J Med Res. 1996;1:331-3.

33. Bossink A, Groeneveld A, Thijs L. Prediction of microbial infection and mortality in medical patients with fever: plasma procalcitonin, neutrophilic elastase-alpha-antitrypsin, and lactoferrin compared with clinical variables. Clin Infect Dis. 1999;29:398-407.

34. Sudhir U, Venkatachalaiah R, Kumar TA, Rao MY, Kempegowda P. Significance of serum procalcitonin in sepsis. Indian J Crit Care Med. 2011;15:1-5.

35. Ugarte $H$, Silva E, Mercan D, De Mendonça A, Vincent JL. Procalcitonin used as a marker of infection in the intensive care unit. Crit Care Med. 1999;27:498-504.

36. Muller B, Becker K, Schachinger H, Rickenbacher PR, Huber PR, Zimmerli W, et al. Calcitonin precursors are reliable markers of sepsis in a medical intensive care unit. Crit Care Med. 2000;28:977-83.

37. Aouifi A, Piriou V, Bastien O, Blanc P, Bouvier H, Evans R, et al. Usefulness of procalcitonin for diagnosis of infection in cardiac surgical patients. Crit Care Med. 2000;28:3171-6.

38. Ruokonen E, Ilkka L, Niskanen M, Takala J. Procalcitonin and neopterin as indicators of infection in critically ill patients. Acta Anaesthesiol Scand. 2002:46:398-404.

39. Giamarellos-Bourboulis E, Mega A, Grecka A, Scarpa N, Koratzanis G, Thomopoulos G, et al. Procalcitonin: a marker to clearly differentiate systemic inflammatory response syndrome and sepsis in the critically ill patient? Intensive Care Med. 2002;28:1351-6.

40. Whang K, Steinwald P, White J, Nylen ES, Snider RH, Simon GL, et al. Serum calcitonin precursors in sepsis and systemic inflammation. J Clin Endocrinol Metab. 1998;83:3296-301.

41. Oberhoffer M, Russwurm S, Bredle D, Chatzinicolaou K, Reinhart K Discriminative power of inflammatory markers for prediction of tumor necrosis factor-a and interleukin-6 in ICU patients with systemic inflammatory response syndrome (SIRS) or sepsis at arbitrary time points. Intensive Care Med. 2000;26:5170-4.

42. Wanner G, Keel M, Steckholzer U, Beier W, Stocker R, Ertel W. Relationship between procalcitonin plasma levels and severity of injury, sepsis, organ failure, and mortality in injured patients. Crit Care Med. 2000;28:950-7.

43. Tugrul S, Esen F, Celebi S, Ozcan PE, Akinci O, Cakar N, et al. Reliability of procalcitonin as a severity marker in critically ill patients with inflammatory response. Anaesth Intensive Care. 2002;30:747-54.

44. Hensler T, Sauerland S, Lefering R, Nagelschmidt M, Bouillon B, Andermahr $J$, et al. The clinical value of procalcitonin and neopterin in predicting sepsis and organ failure after major trauma. Shock. 2003;20:420-6.
45. Mokart D, Merlin M, Sannini A, Brun JP, Delpero JR, Houvenaeghel G, et al Procalcitonin, interleukin 6 and systemic inflammatory response syndrome (SIRS): early markers of postoperative sepsis after major surgery. $\mathrm{Br} J$ Anaesth. 2005;94:767-73.

46. Brunkhorst F, Wegscheider K, Forycki Z, Brunkhorst R. Procalcitonin for early diagnosis and differentiation of SIRS, sepsis, severe sepsis, and septic shock Intensive Care Med. 2000;26 Suppl 2:S148-52.

47. Suprin E, Camus C, Gacouin A. Procalcitonin: a valuable indicator of infection in a medical ICU? Intensive Care Med. 2000;26:1232-8.

48. Meisner M, Rauschmayer C, Schmidt J, Feyrer R, Cesnjevar R, Bredle D, et al. Early increase in procalcitonin after cardiovascular surgery in patients with postoperative complications. Intensive Care Med. 2002;28:1094-102.

49. De Talance N, Burlet C, Claudel C. La procalcitonine (PCT) est-elle le marqueur specifique du choc septique? Immunoanalyse et Biol Special. 2003;18:120-2

50. Luzzani A, Polati E, Dorizzi R, Rungatscher A, Pavan R, Merlini A. Comparison of procalcitonin and C-reactive protein as markers of sepsis. Crit Care Med. 2003;31:1737-41.

51. Du B, Pan J, Chen D, Li Y. Serum procalcitonin and interleukin-6 levels may help to differentiate systemic inflammatory response of infectious and noninfectious origin. Chin Med J. 2003;116:538-42.

52. Geppert A, Steiner A, Delle-Karth G, Heinz G, Huber K. Usefulness of procalcitonin for diagnosing complicating sepsis in patients with cardiogenic shock. Intensive Care Med. 2003;29:1384-9.

53. Endo S, Aikawa N, Fujishima S. Usefulness of procalcitonin serum level for the discrimination of severe sepsis from sepsis: a multicenter prospective study. J Infect Chemother. 2008;14:244-9.

54. Meynaar I, Droog W, Batstra M, Vreeded R, Herbrink P. In critically ill patients, serum procalcitonin is more useful in differentiating between sepsis and SIRS than CRP, II-6, or LBP. Crit Care Res Pract. 2011;2011:594-645.

55. Lee WS, Kang DW, Back JH, Kim HL, Chung JH, Shin BC. Cutoff value of serum procalcitonin as a diagnostic biomarker of infection in end-stage renal disease patients. Korean J Intern Med. 2015;30:198-204.

56. Deng S, Zhu H, Wang K, Cao T. Procalcitonin as a marker of sepsis and outcome in patients with neurotrauma: an observation study. BMC Anesthesiol. 2013;13:48-51.

57. Muller F, Christ-Crain M, Bregenzer T, Krause M, Zimmerli W, Mueller B. Procalcitonin levels predict bacteremia in patients with community-acquired pneumonia: a prospective cohort trial. Chest. 2010;138:121-9.

58. Friederichs J, Hutter M, Hierholzer C, Novotny A, Friess H, Buhren V. Procalcitonin ratio as a predictor of successful surgical treatment of severe necrotizing soft tissue infections. Am J Surg. 2013;206:368-73.

59. Hatherill M, Tibby SM, Turner C, Ratnavel N, Murdoch IA. Procalcitonin and cytokine levels: relationship to organ failure and mortality in pediatric septic shock. Crit Care Med. 2000;28:2591-4.

60. Seligman R, Meisner M, Lisboa TC, Hertz FT, Filippin TB, Fachel JM. Decreases in procalcitonin and C-reactive protein are strong predictors of survival in ventilator-associated pneumonia. Crit Care. 2006;10:R125.

61. Magrini L, Travaglino F, Marino R, Ferri E, DeBerardinis B, Cardelli P. Procalcitonin variations after emergency department admission are highly predictive of hospital mortality in patients with acute infectious disease. Eur Rev Med Pharmacol Sci. 2013;17(S1):133-42.

\section{Submit your next manuscript to BioMed Central and take full advantage of:}

- Convenient online submission

- Thorough peer review

- No space constraints or color figure charges

- Immediate publication on acceptance

- Inclusion in PubMed, CAS, Scopus and Google Scholar

- Research which is freely available for redistribution 